\title{
A New Simplified Dynamic Algorithm for Energy Estimation in Buildings: Description and Validation
}

\author{
Daniele Testi ${ }^{1}$, Michele Barbieri ${ }^{1}$, Eva Schito ${ }^{1}$, Paolo Conti ${ }^{1}$, Paolo Signoretti ${ }^{2}$ \\ ${ }^{1}$ University of Pisa, DESTEC, Pisa, Italy \\ ${ }^{2}$ ENEA, Casaccia Research Center, Rome, Italy
}

\begin{abstract}
Among other energy savings policies, European Directive 2018/884 promotes the adoption of building energy audits. In this perspective, the development of accurate, but simplified dynamic energy simulation tools is a fundamental step to reduce the costs of energy audits and consequently increase their diffusion, especially at the professional level. This paper presents SEAS Light, a simplified dynamic tool that estimates building heating and cooling energy demands. 75 test cases associated to typical Italian climates and building structures have been performed. SEAS Light results are compared with the ones obtained through the full dynamic energy software TRNSYS 17. The validation procedure shows that the proposed routine can evaluate both seasonal heating and cooling energy demands with a good accuracy, using three tuning coefficients presented in the manuscript.
\end{abstract}

\section{Introduction and state of the art}

In Europe, half of the total energy use regards heating and cooling duties, and $80 \%$ of that share accounts for the thermal energy demand of buildings (European Directive (EU) 2018/844). In order to improve energy efficiency and achieve energy savings, Directive 2018/844 confirms the following requests concerning energy audits, already reported in 2012: for large enterprises, the obligation to undergo energy audits, and for Member States the requirement to promote and guarantee the availability of energy audit among households and small-medium enterprises (European Directive 2012/27/EU).

These objectives have been developed with encouraging results in respect of the rate of compulsory energy audits that have been performed by Member States as well as the implementation of national and regional policies of energy audit awareness-raising and promotion via direct financing and cost-sharing (Italy's Energy Efficiency annual report - Executive summary, 2016; Italian Energy Efficiency Action Plan, 2017). In order to guarantee high level results in energy audit, European Directive 2018/844 supposes the auditor to be a trained professional in building energy modelling, able to manage and cluster in a short time a huge quantity of input and output data.

To support the diffusion of energy audits, simple and lowprice tools should be provided for auditors, performing reliable thermal energy flows analysis and proposing specific building retrofit measures (EN 16247-2:2014). Currently, there are two types of tools available for auditors: full dynamic simulation tools and simplified quasi-steady-state tools (EN ISO 13790:2008). The former ones require an in-depth analysis on the specific building, accurate knowledge of inputs and long labour time, evaluating the thermal-energy response on an hourly-or-less timestep; the latter ones evaluate the energy performances typically on a monthly basis, requiring less input data, implementation and computational time; but, generally, their results are less accurate (Schito et al, 2015).

Nowadays, most of the professional software and calculation codes are based on a quasi-steady-state approach, for example, SEAS in Italy, TEE-KENAK in Greece, and EPW in Belgium. The accuracy of these software and the validity of the monthly approach have been investigated by comparison with full dynamic simulation codes. Van der Veken et al (2004) compared the EPW software with TRNSYS and ESP-r, finding good results among three-year simulations in terms of net energy demand. Corrado et al. (2007) compared the ISO 13790 quasi-steady-state method with EnergyPlus, showing that the accuracy of the results is mainly influenced by the simplified assumptions on intermittency and thermal inertia. Pernigotto et al. (2013) compared the results of a quasi-steady-state model with a TRNSYS simulation in terms of thermal gain estimates (both solar and internal ones). They also developed some correction correlations to reduce the discrepancies between the outputs of the two simulation tools. Testi et al. (2013) validated SEAS using TRNSYS on a test case, finding good results both on terms of energy balance and energy fluxes through external components. In a successive work, Schito et al. (2015) found that SEAS is not accurate in case of intermittently-heated high thermal inertia buildings. Similar issues in the use of quasi-steady-state software were found by Evangelisti et al. (2014).

Full dynamic models and routines overcome the limits of the quasi-steady-state approach, providing accurate results in both simulation of the temperature evolutions and energy fluxes due to the use of many nodes (i.e. thermal networks) and shorter space and time scales (Coakley et al., 2014). These tools are also used to design and analyse the feasibility of energy efficiency actions (Testi et al. 2014, Schito et al. 2018a), integrated RES systems (Conti et al. 2019, Grassi et al. 2015, Testi et al. 2016a, Testi et al. 2016b), and advanced control strategies (D'Ettorre et al. 2018, D'Ettorre et al. 2019, Schito et al. 2018b, Testi et al. 2015a). 
On the other hand, accurate models require a notable computational effort and a complete knowledge of a wide set of input parameters, such as building characteristics, meteorological data, HVAC schedules, profiles and manufacturers' data (Zhao et al., 2012; Coakley et al., 2014, Testi et al., 2014). In some cases, the necessity of thousands of inputs, the implementation time, and the computational time are the main criticalities limiting a widespread utilization of these tools (Coakley et al, 2014). Crawley et al. (2008) proposed an overview on twenty building simulation programs. Among the others, DOE-2, EnergyPlus, TRNSYS and ESP-r are the most common tools used for energy audits (Coakley et al, 2014). Also, other methods using lumped RC models are present in literature. For example, Kramer et al (2012) specifically reviewed simplified building models, introducing blackbox models such as the neural network approach and the linear parametrization one, and the lumped capacitance or RC white-box model. Danza et al. (2016) defined a 3resistance and 2-capacitance prediction model, showing the comparison between internal wall surface temperature estimated by the lumped RC model and measured data; Date et al. (2016) provide a multi-level model predictive control strategy, in which the user can switch between detailed and simpler RC models. Buonomano et al. (2014) introduced DETECt, a dynamic simulation code that employs a high-order thermal RC network in which every layer of a building element is characterized by two resistance and one capacity. All these RC models provide good results referring to the reported benchmark case studies, but a software with user interfaces and customization capabilities is still lacking.

The presented literature review confirms that the diffusion of the building dynamic simulation and energy audits at both research and professional level would take advantage of the development of simplified dynamic tools that provide sufficiently accurate results but require a low amount of input data and short implementation and computational times.

In this perspective, the present work introduces the physical and mathematical model used in SEAS Light, a dynamic simulation software for building energy audit developed in MATLAB environment. It is a simplified dynamic model that calculates building hourly energy requirements, but, with respect to full dynamic models, it requires a much smaller amount of input data. The model is based on a single lumped capacity node and needs only three tuning coefficients. With respect to previously mentioned white-box models, the amount of inputs is reduced, as well as the number of equations. If SEAS Light can correctly estimate energy demands, this would hint that the proposed model is strongly physically based. Hence, in this case, the model outputs following the calibration phase are expected to be more robust when compared to black-box models. The software can be easily employed in arbitrary cases and uses a tuning procedure based on data commonly available in energy bills.

In the following section, the dynamic model of SEAS Light is presented and discussed. Next, a description of the tuning procedure is reported. Finally, the software is validated through the prescriptions of European Standard EN 15265:2007 and through the comparison with the results obtained by 75 TRNSYS dynamic simulations.

\section{The model}

SEAS Light considers the whole building as a single lumped capacity node associated to the temperature $T_{z}$. Some broad simplifications of the model have been used in other works (e.g., Lü et al., 2006). The main objective of the model is to estimate the heating/cooling demands of the zone, which can be evaluated as follows:

$$
Q_{H / C, z}^{t}=Q_{A}^{t}+Q_{B}^{t}
$$

The term $Q_{A}^{t}$ refers to the balance between energy losses and gains; the term $Q_{B}^{t}$ refers to the variation of internal energy of the zone. The term $Q_{A}$ reads:

$$
Q_{A}^{t}=\beta_{\mathrm{H} / C} \sum_{\mathrm{l}}^{5} \dot{Q}_{l}^{t} \Delta t
$$

where the five terms $\dot{Q}_{l}$ are described next, and $\Delta t$ is the hourly simulation time step. The evolution of the zone tempeature $T_{z}$ reads:

$$
T_{z}^{t+1}=\left\{\begin{array}{cl}
T_{z}^{t}+\frac{\sum \dot{Q}_{A}^{\mathrm{t}}}{K_{z}} \Delta t, & T_{z}^{t}+\frac{\sum \dot{Q}_{A}^{\mathrm{t}}}{K_{z}} \Delta t \geq T_{H}^{\text {set }} \\
T_{H}^{\text {set }}, & \text { otherwise }
\end{array}\right.
$$

in the heating period, and:

$$
T_{z}^{t+1}=\left\{\begin{array}{c}
T_{z}^{t}+\frac{\sum \dot{Q}_{A}^{\mathrm{t}}}{K_{z}} \Delta t, \quad T_{z}^{t}+\frac{\sum \dot{Q}_{A}^{\mathrm{t}}}{K_{z}} \Delta t \leq T_{C}^{\text {set }} \\
T_{C}^{\text {set }}, \text { otherwise }
\end{array}\right.
$$

in the cooling period. $T_{H / C}^{s e t}$ are the indoor set-points in the heating $(H)$ or cooling $(C)$ period, $K_{z}$ is the equivalent thermal capacity of the whole building, and $\beta_{H / C}$ are proper tuning parameters, furtherly discussed in a following subsection. The equivalent thermal capacity, $K_{z}$, is evaluated as:

$$
K_{z}=\sum_{p} K_{\text {int }_{p}} A_{p}
$$

where $K_{\text {int }_{p}}$ is the areal heat capacity of the wall $p$ (internal side), as defined in EN ISO 13786:2007, and $A_{p}$ is the area of the opaque surface of the wall $p$. The term $Q_{B}$ reads:

$$
Q_{B}^{\mathrm{t}}=\left\{\begin{aligned}
0, & \text { if } T_{z}^{\mathrm{t}} \geq T_{H}^{s e t} \\
\beta_{H} K_{z}\left(T_{H}^{s e t}-T_{z}^{t}\right), & \text { otherwise }
\end{aligned}\right.
$$

in the heating period, and:

$$
Q_{B}^{\mathrm{t}}=\left\{\begin{aligned}
0, & T_{z}^{\mathrm{t}} \leq T_{C}^{\text {set }} \\
\beta_{C} K_{z}\left(T_{z}^{t}-T_{C}^{s e t}\right), & \text { otherwise }
\end{aligned}\right.
$$

in the cooling period.

When the thermal system is switched-off, $Q_{H / C, Z}^{t}$ is equal to zero and the evolution of $T_{Z}$ is evaluated with the first case of Eqs. (3).

The five terms $\dot{Q}_{l}$ in Eq. (2) are i) the thermal power exchanged through the opaque walls, ii) the thermal losses through the windows and glazed surfaces, iii) the thermal losses due to ventilation, iv) the thermal gains due to solar radiation through glazed surfaces, and v) the internal heat gains (e.g., people and appliances). 
Thermal losses through the opaque walls, $\dot{Q}_{l=1}$

The term $\dot{Q}_{l=1}$ considers the heat flux through the opaque external elements, including the long-wavelength thermal radiation, $\dot{Q}_{s k y}$, and the global normal solar radiation $\dot{I}$. It is defined as the sum of a steady-state contribution, $\dot{Q}_{\text {stat }, p}$, and a dynamic one, $\dot{Q}_{d y n, p}$ :

$$
\dot{Q}_{l=1}^{\mathrm{t}}=\sum_{p}\left(\dot{Q}_{\text {stat }, p}^{\mathrm{t}}+\dot{Q}_{\text {dyn,p }}^{t}\right)
$$

The first term is the steady-state term for the generic external opaque surface $p$. It is calculated as the product between the overall steady-state thermal transmittance

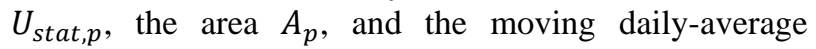
difference $\overline{\Delta T}_{\text {stat }, p}^{t}$ :

$$
\begin{aligned}
& \dot{Q}_{\text {stat }, p}^{t}=U_{\text {stat }, p} A_{p} \overline{\Delta T}_{\text {stat }, p}^{t} \\
& \overline{\Delta T}_{\text {stat }, p}^{t}=\frac{1}{24} \sum_{t-24}^{t}\left(T_{\text {sol-air }, p}^{t}-T_{z}^{t}\right)
\end{aligned}
$$

The dynamic term $\dot{Q}_{d y n, p}$ is defined as the product between the periodic thermal transmittance $U_{d y n, p}$, the area $A_{p}$, and the temperature difference $\overline{\Delta T}_{d y n, p}$ :

$$
\begin{gathered}
\dot{Q}_{\text {dyn,p }}^{t}=U_{\text {dyn,p }} A_{p} \Delta T_{d y n, p}^{t} \\
\overline{\Delta T}_{d y n, p}=\bar{T}_{\text {sol-air, }, p}^{t}-T_{\text {sol-air }, p}^{t-\phi}
\end{gathered}
$$

The periodic thermal transmittance $U_{d y n, p}$ and time shift $\phi$ of walls are defined and calculated according to the technical standard EN ISO 13786:2007.

The sol-air temperature $T_{\text {sol-air }}$ is defined as (D.G. Stephenson, 1957; O’Callaghan et al., 1977):

$$
\begin{gathered}
T_{\text {sol-air }}=T_{\text {ext }}+\frac{1}{h_{\text {ext }}}\left(\alpha_{s} F_{s h, o b} \dot{I}-\dot{Q}_{s k y}\right) \\
\dot{Q}_{s k y}=F V \varepsilon \sigma\left[T_{\text {ext }}^{4}-T_{s k y}^{4}\right] \\
F V=F_{s h, o b}^{\text {diff } \frac{1+\cos \left(\beta_{S}\right)}{2}}
\end{gathered}
$$

where $T_{\text {ext }}$ is the outdoor temperature, $F_{s h, o b}$ is the shading reduction factor, $\dot{I}$ is the normal global solar radiation, $h_{\text {ext }}$ is the external heat transfer coefficient, $\alpha_{s}$ is the solar radiation absorptivity, $\varepsilon$ is the surface emissivity, $\sigma$ is the Stefan-Boltzmann constant, $T_{\text {sky }}$ is the apparent sky temperature (EN ISO 13790:2008), FV is the form factor between the building element and the sky, which accounts for the surface tilt angle, $\beta_{S}$, and the shading reduction factor for the diffuse radiation, $F_{s h, o b}^{\text {diff }}$. All the shading factors in Eqs. $(11-13)$ are calculated according to UNI/TS 11300-1:2014.

Thermal losses through the ground are calculated as:

$\dot{Q}_{\text {stat }, \text { floor }}^{t}=b_{\text {tr }, U} U_{\text {stat }, \text { floor }} A_{\text {floor }}\left(T_{z}^{\mathrm{t}}-T_{\text {avg,floor }}\right)$

where $T_{\text {avg,floor }}$ is the monthly average outdoor temperature, and $b_{t r, U}$ is the correction factor defined in UNI/TS 11300-1:2014 for ground heat transfer.

\section{Thermal losses through the windows and glazed} surfaces, $\dot{Q}_{l=2}$

The term $\dot{Q}_{l=2}$ is calculated as:

$$
\dot{Q}_{l=2}^{\mathrm{t}}=\sum_{w} U_{s h, w}^{t} A_{w}\left(T_{z}^{\mathrm{t}}-T_{e x t}^{\mathrm{t}}\right)
$$

where $A_{w}$ is the area of the $w-t h$ window (frame included). The overall steady-state thermal transmittance
$U_{s h, w}^{t}=\frac{1}{U_{q}}+R_{s h, q}$ includes overall steady-state thermal transmittance of the window and the additional thermal resistance of shutters, $R_{s h, q}^{t}$. The latter term is zero if shutters are open at the time $t$.

Thermal losses due to ventilation, $\dot{Q}_{l=3}$

The term $\dot{Q}_{l=3}$ is evaluated as:

$$
\dot{Q}_{l=3}^{\mathrm{t}}=\dot{m}_{v e n t}^{t} c_{p, a i r}\left(T_{e x t}^{\mathrm{t}}-T_{z}^{\mathrm{t}}\right)
$$

where $\dot{m}_{\text {vent }}^{t}$ and $c_{p \text {,air }}$ are the mass flow rate and the specific heat at constant pressure of external air.

Thermal gains due to solar radiation through glazed surfaces, $\dot{Q}_{l=4}$

The term $\dot{Q}_{l=4}$ is evaluated as:

$$
\begin{gathered}
\dot{Q}_{l=4}=\alpha_{S O L_{C}} \times \\
{\left[\sum_{w} g_{w} F_{s h, o b, w} F_{s h, g l, w}\left(1-F_{f, w}\right) A_{w} \dot{I}_{w}\right]}
\end{gathered}
$$

where $g$ is the solar energy transmittance of the element, $F_{s h, o b}$ is the shading reduction factor, $F_{s h, g l}$ is the shutter reduction factor (UNI/TS 11300-1:2014), and $F_{f}$ is the ratio between frame and total window area. The term $\alpha_{\mathrm{SOL}_{C}}$ is a tuning parameter, discussed hereafter.

Internal heat gains, $\dot{\boldsymbol{Q}}_{\boldsymbol{l}=\mathbf{5}}$

Heat gain profiles, $\dot{Q}_{l=5}^{t}$, from occupants, electrical devices, and lighting are user-defined inputs of the model.

\section{Dynamic tuning coefficients, $\beta_{H}, \beta_{C}$ and $\alpha_{S O L_{C}}$}

The model introduces three dynamic tuning coefficients $\beta_{H}, \beta_{C}$ and $\alpha_{S O L_{C}}$. The first and the second ones refer to the equivalent thermal zone capacity (Eqs. 5), while the third one modifies the solar gains through the windows (Eq. 17). SEAS Light includes a calculation routine to calculate the coefficients $\beta_{H}, \beta_{C}$ and $\alpha_{S O L_{C}}$ from energy billings.

\section{Dynamic simulation and evaluation of the three tuning parameters}

SEAS Light calculates the results through a three-step procedure:

1. All tuning parameters are set equal to 1 and the first simulation runs. The simulated cooling energy demand, $Q_{C, Z, T O T}^{I}=\sum_{t}\left(Q_{C, z}^{t}\right)$, is compared with a reference value, $Q_{C, R E F}$, obtained from energy bills and an estimated cooling system efficiency:

$$
\operatorname{err}_{S O L}^{I}=\frac{Q_{C, Z, T O T}^{I}-Q_{C, R E F}}{Q_{C, R E F}}
$$

An updated value of the solar gains tuning parameter is then calculated as:

$$
\alpha_{S O L}^{I}=\frac{\alpha_{S O L}}{1+\mathrm{e} r r_{S O L}^{I}}
$$

2. The capacity tuning parameters $\beta_{C}$ and $\beta_{H}$ are again set to 1 , while the solar gain through windows parameter is set equal to $\alpha_{S O L}^{I}$. A new simulation runs, and the following errors are calculated on the basis of the updated values of $Q_{H, Z}^{I I}$ and $Q_{C, Z}^{I I}$

$$
\operatorname{err}_{H}^{I I}=\frac{Q_{H, z, T O T}^{I I}-Q_{H, R E F}}{Q_{H, R E F}}
$$




$$
\operatorname{err}_{C}^{I I}=\frac{Q_{C, Z, T O T}^{I I}-Q_{C, R E F}}{Q_{C, R E F}}
$$

$Q_{H, R E F}$ is obtained from energy bills and assuming an overall heating system efficiency. The new values for the tuning parameters are:

$$
\begin{aligned}
& \beta_{H}^{I I}=\frac{\beta_{H}}{1+e r r_{H}^{I I}} \\
& \beta_{C}^{I I}=\frac{\beta_{C}}{1+e r r_{C}^{I I}}
\end{aligned}
$$

3. The third iteration runs with the tuning parameters set equal to $\alpha_{S O L}^{I}, \beta_{H}^{\mathrm{II}}$, and $\beta_{C}^{\mathrm{II}}$. The final results are the values of the seasonal thermal energy demand for heating, $Q_{H, Z, T O T}^{I I I}$, and cooling, $Q_{C, Z, T O T}^{I I I}$, and the following errors:

$$
\begin{aligned}
& e r r_{H}^{I I I}=\frac{Q_{H, Z, T O T}^{I I I}-Q_{H, R E F}}{Q_{H, R E F}} \\
& e r r_{C}^{I I I}=\frac{Q_{C, Z, T O T}^{I I I}-Q_{C, R E F}}{Q_{C, R E F}}
\end{aligned}
$$

Steps two and three can be repeated to furtherly decrease the deviation between SEAS results and reference values. When the seasonal cooling energy demand of the zone is less than $100 \mathrm{kWh} / y e a r$, the tuning procedure is skipped, because it would result in unrealistic values of $\alpha_{\text {sol }_{C}}$ and $\beta_{C}$. In these cases, SEAS Light runs the simulation with all the tuning parameters set to 1 .

\section{Validation according to EN 15265:2007}

SEAS Light has been validated through the 12 test cases proposed by EN 15265:2007. Validation results are shown in Table 1. Resulting tuning parameters have similar values in all test cases, with three exceptions associated to the tests with very low cooling energy loads, where the tuning procedure have not run (less than 100 $\mathrm{kWh} /$ year).

\section{Validation according to TRNSYS results}

SEAS Light has also been compared with the widespread and established dynamic software TRNSYS (version 17). A total of 75 test cases have been analyzed, concerning different typical Italian climates (Catania, Pisa, and Turin), different types of building (flat, villa, office), different building envelopes (uninsulated, insulated walls, single-glazed, double-glazed windows), and different users' thermal zone occupation profiles (family, retirees, workers). During this validation process, TRNSYSgenerated outputs in terms of seasonal thermal energy demand for cooling and heating are respectively assumed as the reference values $Q_{C, R E F}$, and $Q_{H, R E F}$, Tables $2-3$ show the envelope characteristics of simulated buildings. Tables $4-6$ report the values of the tuning parameters for all the 75 test cases, ordered by users' profile, geometry, stratigraphy of walls, and geographic location. In these tables, the name of the test includes the description of the parameters used. For instance, the case "Villa Retiree _ PI_MLPO1_COP04" indicates a villa with a horizontal roof, two retired persons as occupants, located in PISA, made of MLP01 and COP04 as building elements. Additional details on the parameters of the test cases and walls ID are provided hereafter.

Table 1: Validation test results according to EN 15265:2007 (energy values in [kWh]).

\begin{tabular}{|c|c|c|c|c|c|c|c|c|c|}
\hline Test case & $\boldsymbol{\alpha}_{\mathbf{S O L}}$ & $\boldsymbol{\beta}_{\boldsymbol{C}}$ & $\boldsymbol{\beta}_{\boldsymbol{H}}$ & $\boldsymbol{Q}_{\boldsymbol{C} \text { REF }}$ & $\boldsymbol{Q}_{\boldsymbol{C} \text { TOT }}$ & $\boldsymbol{\Delta} \boldsymbol{Q}_{\boldsymbol{C}}[\boldsymbol{\%}]$ & $\boldsymbol{Q}_{\boldsymbol{H} \text { REF }}$ & $\boldsymbol{Q}_{\boldsymbol{H} \text { TOT }}$ & $\boldsymbol{\Delta} \boldsymbol{Q}_{\boldsymbol{H}}[\%]$ \\
\hline 1 & 0.76 & 1.10 & 0.85 & 233.8 & 233.8 & $<0.1$ & 748.00 & 748.00 & $<0.1$ \\
\hline 2 & 0.76 & 1.14 & 0.86 & 200.5 & 200.5 & $<0.1$ & 722.70 & 722.70 & $<0.1$ \\
\hline 3 & 1 & 1 & 1 & 43 & 79.8 & 2.60 & 1368.50 & 1418.20 & 3.52 \\
\hline 4 & 0.79 & 1.11 & 0.72 & 1530.9 & 1530.9 & $<0.1$ & 567.40 & 572.77 & 0.26 \\
\hline 5 & 0.71 & 1.08 & 0.77 & 201.7 & 201.7 & $<0.1$ & 463.10 & 463.16 & $<0.1$ \\
\hline 6 & 0.74 & 1.13 & 0.77 & 185.1 & 185.1 & $<0.1$ & 509.80 & 509.80 & $<0.1$ \\
\hline 7 & 1 & 1 & 1 & 19.5 & 57.5 & 3.49 & 1067.40 & 1080.50 & 1.21 \\
\hline 8 & 0.71 & 1.14 & 0.61 & 1133.2 & 1133.2 & $<0.1$ & 313.20 & 323.04 & 0.68 \\
\hline 9 & 0.71 & 1.08 & 0.71 & 158.3 & 158.3 & $<0.1$ & 747.10 & 747.12 & $<0.1$ \\
\hline 10 & 0.73 & 1.05 & 0.75 & 192.4 & 192.4 & $<0.1$ & 574.20 & 574.22 & $<0.1$ \\
\hline 11 & 1 & 1 & 1 & 14.1 & 49.5 & 2.51 & 1395.10 & 1573.20 & 12.64 \\
\hline 12 & 0.69 & 1.20 & 0.61 & 928.3 & 928.3 & $<0.1$ & 533.50 & 536.77 & 0.22 \\
\hline
\end{tabular}

\begin{tabular}{|c|c|c|c|c|c|}
\hline Type of building & $\begin{array}{c}\text { Internal vertical } \\
\text { walls }\end{array}$ & $\begin{array}{c}\text { External vertical } \\
\text { walls }\end{array}$ & Ceiling / Roof & $\begin{array}{c}\text { Floor against } \\
\text { ground }\end{array}$ & Reference Geometry \\
\hline Office & North, south, east & West & Ceiling & No & EN ISO 13791:2004 \\
\hline Flat & East & North, south, west & Ceiling & No & Testi et al. (2015b) \\
\hline Villa & East & North, south, west & Roof & Yes & EN ISO 13791:2004 \\
\hline
\end{tabular}

Table 3: Typologies of external shutters and internal shading devices

\begin{tabular}{|c|c|c|c|c|c|}
\hline Type of building & External covering & $\boldsymbol{F}_{\text {sh, } q \text { l }}$ external covering & $\boldsymbol{R}_{\text {sh }}$ & Shading device & $\boldsymbol{F}_{\text {sh, }, \boldsymbol{l}}$ shading device \\
\hline Office & Venetian blind & 0.3 & 0 & None & 1 \\
\hline Flat & Roller & 0.3 if partially closed, 0 if & 0.26 & White curtain & 0.8 \\
\hline Villa & Persian blind & 0 & 0 & Velvet curtain & 0.57 \\
\hline
\end{tabular}




\section{Building elements}

All test cases have a simplified box-like structure of the building. Flat, villa and office mainly differ from the number and size of external walls, as reported in Table 2. Thermal characteristics of envelope elements depend on building type and geographic location, according to the library provided in UNI/TR 11552:2014. The name of the test case includes the ID code used in the technical standard, allowing the identification of the element stratigraphy.

Windows are only installed on vertical external surfaces. Test cases implement two typologies of window, taken from TRNSYS 17 libraries (S.A. Klein et al., 2010): TRNSYS 1001, which is a single-glazed window associated to uninsulated vertical walls, and TRNSYS 1002, which is a double-glazed window installed in insulated vertical walls. Table 3 reports the typologies of external shutters and internal shading devices for windows.

\section{Building use, users' profiles, and HVAC operational hours}

The office building is associated to a single person that works from 8 a.m. to 6 p.m. every day except for the weekend.

Villa and flat buildings have three occupation profiles:

1. Retiree: two occupants that stay in the thermal zone almost continuously.

2. Family: four persons that occupy the building from the late afternoon to the early morning on workdays and almost every hour of weekends.
3. Worker: a single occupant that leaves the thermal zone from 8 a.m. to 5 p.m. on workdays and from 10 a.m. to 5 p.m. during weekends.

The values of heat gains per person are taken from EN ISO 13792:2012 and EN ISO 8996:2004.

The occupation profiles also determine the operational scheduling of the heating and cooling systems: the system is active from the hour before the entrance of the occupants in the thermal zone, and it is switched-off when no occupants are inside. In any case, systems can be activated only from 6 a.m. to 10 p.m. The heating and cooling set-points, $T_{H}^{\text {set }}$ and $T_{C}^{\text {set }}$, are set equal to $20{ }^{\circ} \mathrm{C}$ and $26{ }^{\circ} \mathrm{C}$, respectively.

\section{Results of the validation}

Tables $4-6$ show the results of the comparative procedure between SEAS Light and TRNSYS 17. The tuning has been performed in 63 test cases, where the reference values of seasonal demand are higher than 100 $\mathrm{kWh} /$ year. In these cases, SEAS Light results perfectly agree with TRNSYS 17 in terms of both heating and cooling seasonal energy demands. Besides, the values of the tuning parameters are close to 1 , indicating a good robustness of the physical model. The tuning procedure has not been applied to the remaining 12 cases, due to the limited value of the cooling energy demand. In these cases, SEAS Light provides values with the same order of magnitude of TRNSYS results. The tuning parameters reported in Tables $-4-6$ can be considered as suggested values for energy audits of similar building structures, Italian climates, and occupancy profiles when reference measured data (actual energy uses by billings) are not available for the tuning procedure.

Table 4: Simulation results for Pisa (energy values in [kWh]).

\begin{tabular}{|c|c|c|c|c|c|c|c|c|c|}
\hline Test case & $\alpha_{S O L}$ & $\beta_{C}$ & $\boldsymbol{\beta}_{H}$ & $Q_{C_{R E F}}$ & $Q_{C_{-} T O T}$ & $\operatorname{err}_{C}^{I I I}[\%]$ & $Q_{H_{-} R E F}$ & $Q_{H_{-} T O T}$ & $\begin{array}{c}\operatorname{err}_{H}^{I I I} \\
{[\%]}\end{array}$ \\
\hline Office_PI_MLP01 & 0.77 & 1.07 & 0.67 & 564.9 & 564.9 & $<0.1$ & 829.3 & 829.3 & $<0.1$ \\
\hline Office_PI_MCV04 & 0.9 & 1.03 & 0.65 & 731.9 & 731.9 & $<0.1$ & 375.0 & 375.0 & $<0.1$ \\
\hline Flat_Retiree_PI_MLP03 & 0.48 & 1.1 & 0.93 & 622.8 & 622.8 & $<0.1$ & 4947.8 & 4947.8 & $<0.1$ \\
\hline Flat_Retiree_PI_MCV04 & 0.65 & 1.09 & 0.94 & 860.6 & 860.6 & $<0.1$ & 2827.7 & 2827.7 & $<0.1$ \\
\hline Flat_Family_PI_MLP03 & 0.57 & 0.89 & 0.9 & 369.8 & 369.8 & $<0.1$ & 4425.2 & 4425.2 & $<0.1$ \\
\hline Flat_Family_PI_MCV04 & 0.74 & 0.95 & 0.91 & 516.8 & 516.8 & $<0.1$ & 2748.7 & 2748.7 & $<0.1$ \\
\hline Flat_Worker_PI_MLP03 & 1 & 1 & 1 & 97.4 & 243.3 & 149.85 & 5586.6 & 6064.9 & 8.56 \\
\hline Flat_Worker_PI_MCV04 & 0.59 & 1.18 & 0.92 & 130.6 & 130.6 & $<0.1$ & 3966.1 & 3966.1 & $<0.1$ \\
\hline Villa_HR_Retiree_PI_MLP01_COP04 & 0.79 & 0.95 & 0.79 & 318.7 & 318.7 & $<0.1$ & 18202.1 & 18202.1 & $<0.1$ \\
\hline Villa_HR_Retiree_PI_MCV04_COP03 & 0.93 & 1.02 & 0.95 & 211.5 & 211.5 & $<0.1$ & 13276.2 & 13276.2 & $<0.1$ \\
\hline Villa_HR_Family_PI_MLP01_COP04 & 0.58 & 0.72 & 0.69 & 176.2 & 176.2 & $<0.1$ & 15641.4 & 15641.4 & $<0.1$ \\
\hline Villa_HR_Family_PI_MCV04_COP03 & 0.64 & 0.86 & 0.9 & 102.6 & 102.6 & $<0.1$ & 12701.8 & 12701.8 & $<0.1$ \\
\hline Villa_HR_Worker_PI_MLP01_COP04 & 1 & 1 & 1 & 72.3 & 180.5 & 149.54 & 16675.2 & 23871.6 & 43.16 \\
\hline Villa_HR_Worker_PI_MCV04_COP03 & 1 & 1 & 1 & 19.5 & 53.6 & 175.37 & 14109.2 & 15338.6 & 8.71 \\
\hline Villa_INC_Retiree_PI_MLP01_CIN04 & 0.86 & 0.95 & 0.79 & 395.4 & 395.4 & $<0.1$ & 20158.5 & 20158.5 & $<0.1$ \\
\hline Villa_INC_Retiree_PI_MCV04_CIN03 & 0.92 & 1.02 & 0.95 & 209.7 & 209.7 & $<0.1$ & 14283.0 & 14283.0 & $<0.1$ \\
\hline Villa_INC_Retiree_PI_MCV04_CIN02 & 0.68 & 0.97 & 0.92 & 220.6 & 220.6 & $<0.1$ & 14200.8 & 14200.8 & $<0.1$ \\
\hline Villa_INC_Family_PI_MLP01_CINO4 & 0.68 & 0.78 & 0.69 & 244.1 & 244.1 & $<0.1$ & 17185.3 & 17185.3 & $<0.1$ \\
\hline Villa_INC_Family_PI_MCV04_CIN03 & 0.64 & 0.85 & 0.9 & 105.5 & 105.5 & $<0.1$ & 13659.8 & 13659.8 & $<0.1$ \\
\hline Villa_INC_Family_PI_MCV04_CIN02 & 0.49 & 0.7 & 0.89 & 117.2 & 117.2 & $<0.1$ & 13536.0 & 13536.0 & $<0.1$ \\
\hline Villa_INC_Worker_PI_MLP01_CIN04 & 0.53 & 0.65 & 0.69 & 122.1 & 122.1 & $<0.1$ & 18168.3 & 18168.3 & $<0.1$ \\
\hline Villa_INC_Worker_PI_MCV04_CIN03 & 1 & 1 & 1 & 23.5 & 58.3 & 147.85 & 15066.5 & 16329.4 & 8.38 \\
\hline Villa_INC_Worker_PI_MCV04_CIN02 & 1 & 1 & 1 & 28.5 & 102.5 & 259.49 & 14932.6 & 16438.6 & 10.09 \\
\hline
\end{tabular}


Table 5: Simulation results for Catania (energy values in [kWh]).

\begin{tabular}{|c|c|c|c|c|c|c|c|c|c|}
\hline Test case & $\alpha_{S O L}$ & $\boldsymbol{\beta}_{C}$ & $\beta_{H}$ & $Q_{C_{-} R E F}$ & $Q_{C_{-} T O T}$ & $\begin{array}{c}\operatorname{err}_{C}^{I I I} \\
{[\%]}\end{array}$ & $Q_{H_{-} R E F}$ & $Q_{H_{-} T O T}$ & $\begin{array}{c}\boldsymbol{e} \boldsymbol{e r r}_{H}^{\boldsymbol{I I I}} \\
{[\%]}\end{array}$ \\
\hline Office_CT_MCO03 & 0.82 & 0.98 & 0.46 & 748.6 & 748.6 & $<0.1$ & 320.2 & 320.2 & $<0.1$ \\
\hline Office_CT_MCV03 & 0.9 & 1 & 0.35 & 825.9 & 825.9 & $<0.1$ & 123.0 & 123.0 & $<0.1$ \\
\hline Flat_Retiree_CT_MLP03 & 0.73 & 0.88 & 0.96 & 1345.1 & 1345.1 & $<0.1$ & 2543.1 & 2543.1 & $<0.1$ \\
\hline Flat_Retiree_CT_MCV03 & 0.82 & 0.92 & 0.91 & 1367.8 & 1367.8 & $<0.1$ & 1727.7 & 1727.7 & $<0.1$ \\
\hline Flat_Family_CT_MLP03 & 0.8 & 0.85 & 0.88 & 954.6 & 954.6 & $<0.1$ & 2350.1 & 2350.1 & $<0.1$ \\
\hline Flat_Family_CT_MCV03 & 0.86 & 0.9 & 0.85 & 998.2 & 998.2 & $<0.1$ & 1735.3 & 1735.3 & $<0.1$ \\
\hline Flat_Worker_CT_MLP03 & 0.82 & 0.86 & 0.9 & 455.9 & 455.9 & $<0.1$ & 3414.9 & 3414.9 & $<0.1$ \\
\hline Flat_Worker_CT_MCV03 & 0.88 & 0.91 & 0.9 & 460.1 & 460.1 & $<0.1$ & 2830.7 & 2830.7 & $<0.1$ \\
\hline Villa_HR_Retiree_CT_MLP01_COP04 & 0.85 & 0.89 & 0.77 & 2251.8 & 2251.8 & $<0.1$ & 10223.7 & 10223.7 & $<0.1$ \\
\hline Villa_HR_Retiree_CT_MCV03_COP04 & 0.87 & 0.9 & 0.94 & 2139.0 & 2139.0 & $<0.1$ & 10036.8 & 10036.8 & $<0.1$ \\
\hline Villa_HR_Family_CT_MLP01_COP04 & 0.71 & 0.73 & 0.67 & 1569.3 & 1569.3 & $<0.1$ & 8988.9 & 8988.9 & $<0.1$ \\
\hline Villa_HR_Family_CT_MCV03_COPO4 & 0.75 & 0.77 & 0.89 & 1573.6 & 1573.6 & $<0.1$ & 9532.7 & 9532.7 & $<0.1$ \\
\hline Villa_HR_Worker_CT_MLP01_COP04 & 0.65 & 0.67 & 0.69 & 1147.7 & 1147.7 & $<0.1$ & 10015.9 & 10015.9 & $<0.1$ \\
\hline Villa_HR_Worker_CT_MCV03_COP04 & 0.7 & 0.72 & 0.91 & 1148.5 & 1148.5 & $<0.1$ & 10841.8 & 10841.8 & $<0.1$ \\
\hline Villa_INC_Retiree_CT_MLP01_CINO4 & 0.87 & 0.9 & 0.76 & 2564.9 & 2564.9 & $<0.1$ & 11283.0 & 11283.0 & $<0.1$ \\
\hline Villa_INC_Retiree_CT_MCV03_CINO4 & 0.89 & 0.91 & 0.94 & 2452.0 & 2452.0 & $<0.1$ & 11348.1 & 11348.1 & $<0.1$ \\
\hline Villa_INC_Family_CT_MLP01_CIN04 & 0.72 & 0.75 & 0.67 & 1826.9 & 1826.9 & $<0.1$ & 9824.5 & 9824.5 & $<0.1$ \\
\hline Villa_INC_Family_CT_MCV03_CINO4 & 0.76 & 0.78 & 0.89 & 1835.5 & 1835.5 & $<0.1$ & 10699.7 & 10699.7 & $<0.1$ \\
\hline Villa_INC_Worker_CT_MLP01_CIN04 & 0.68 & 0.7 & 0.68 & 1406.7 & 1406.7 & $<0.1$ & 10812.7 & 10812.7 & $<0.1$ \\
\hline Villa_INC_Worker_CT_MCVO3_CIN04 & 0.73 & 0.75 & 0.91 & 1413.7 & 1413.7 & $<0.1$ & 11991.6 & 11991.6 & $<0.1$ \\
\hline
\end{tabular}

Table 6: Simulation results for Turin (Energy values in [kWh]).

\begin{tabular}{|c|c|c|c|c|c|c|c|c|c|}
\hline Test case & $\alpha_{S O L}$ & $\beta_{C}$ & $\beta_{H}$ & $Q_{C_{-} \text {REF }}$ & $Q_{C_{-} T O T}$ & $\begin{array}{c}\boldsymbol{e r r} I_{C}^{I I I} \\
{[\%]}\end{array}$ & $Q_{H_{-} R E F}$ & $Q_{H_{-} T O T}$ & $\begin{array}{c}\boldsymbol{e r r} I_{H}^{I I I} \\
{[\%]}\end{array}$ \\
\hline Office_TO_MCV04 & 0.76 & 1.02 & 0.8 & 501.6 & 501.6 & $<0.1$ & 896.8 & 896.8 & $<0.1$ \\
\hline Office_TO_MPF03 & 0.75 & 1.02 & 0.8 & & 499.1 & $<0.1$ & 907.6 & & $<0.1$ \\
\hline Flat_Retiree_TO_MCV04 & 0.64 & 0.98 & 0.97 & 664.1 & 664.1 & $<0.1$ & 5218.1 & 5218.1 & $<0.1$ \\
\hline Flat_Retiree_TO_MCO05 & & 0.99 & & 695.4 & 695.4 & $<0.1$ & 4894.3 & 4894.3 & $<0.1$ \\
\hline Flat_Family_TO_MCV04 & 73 & 0.86 & 0.94 & 407.0 & 407.0 & $<0.1$ & 4821.1 & & $<0.1$ \\
\hline Flat_Family_TO_MCO05 & 0.75 & 0.87 & 0.95 & 425.7 & 425.7 & $<0.1$ & & & $<0.1$ \\
\hline Flat_Worker_TO_MCV04 & 1 & 1 & 1 & 97.6 & 148.0 & 51.7 & 074.8 & & 4.85 \\
\hline Flat_Worker_TC & 0.74 & 0.91 & 0.96 & 107.0 & 107.0 & $<0.1$ & 5768.0 & & $<0.1$ \\
\hline Villa_HR_Retiree_TO_N & .74 & 0.87 & 0.8 & 653.7 & 653.7 & $<0.1$ & & & $<0.1$ \\
\hline Villa_HR_Retiree_TO_MCV04_COP03 & 0.83 & 0.97 & 0.95 & 441.7 & 441.7 & $<0.1$ & & & $<0.1$ \\
\hline Villa_HR_Retiree_T & & 0.99 & & & 456.2 & $<0.1$ & & & $<0.1$ \\
\hline Villa_HR_Family_T & & 0.66 & 0.69 & & 364.1 & $<0.1$ & & & $<0.1$ \\
\hline Villa_HR_Family_TO_M & 0. & 0.78 & 0.9 & & & & & & $<0.1$ \\
\hline Villa_HR_Family_TO_M & & 0.83 & 0.9 & & 222.1 & $<0.1$ & & & $<0.1$ \\
\hline Villa_HR_Work & 0.47 & 0.53 & 0.7 & 193 & 193.5 & $<0.1$ & & & $<0.1$ \\
\hline Villa_HR_Worker_TO_M & 1 & 1 & 1 & & 136.4 & 117.64 & 203 & 3.0 & 8.61 \\
\hline Villa_HR_Worker_TO_MCO05_COP03 & 1 & 1 & 1 & .4 & 120.4 & 89.78 & 18991.0 & 0647.3 & 8.72 \\
\hline Villa_INC_Retiree_TO_MLP01_CIN04 & 0.78 & 0.88 & 0.8 & & 766.0 & $<0.1$ & & & $<0.1$ \\
\hline Villa_INC_Reti & & 0.97 & 0.96 & 447.2 & 447.2 & $<0$. & 7.6 & 1497.6 & $<0.1$ \\
\hline Villa_INC_Retiree_TO_MCV04_CINO2 & 0.71 & 0.91 & 0.93 & 461.8 & 461.8 & $<0.1$ & 21381.8 & 1381.8 & $<0.1$ \\
\hline Villa_INC_Retiree_TO_MCO05_CIN03 & 0.88 & 0.99 & 0.96 & 462.1 & 462.1 & $<0.1$ & 19948.0 & 9948.0 & $<0.1$ \\
\hline Villa_INC_Retiree_T & & 0.94 & 0.93 & & & & & & $<0.1$ \\
\hline Villa_INC_Family_TO_MLP01_CIN04 & 0.63 & 0.69 & 0.69 & 460.4 & 460.4 & $<0$ & 2549 & 5498.8 & $<0.1$ \\
\hline Villa_INC_Family_TO_MCV04_CIN03 & 0.69 & 0.79 & 0.91 & 231.9 & 231.9 & $<0.1$ & 20251.7 & 20251.7 & $<0.1$ \\
\hline Villa_INC_Family_TO_MCV04_CIN02 & 0.58 & 0.68 & 0.89 & 240.0 & 240.0 & $<0.1$ & 20159.7 & 0159.7 & $<0.1$ \\
\hline Villa_INC_Family_TO_MCO05_CIN03 & 0.7 & 0.83 & 0.91 & 232.8 & 232.8 & $<0$. & & 8899.7 & $<0.1$ \\
\hline Villa_INC_Family_TO_MCO05_C & 0.6 & 0.73 & 0.89 & 249.1 & 249.1 & $<0$ & 18772.2 & 18772.2 & $<0.1$ \\
\hline Villa_INC_Worker_TO_MLP01_CIN04 & 0.55 & 0.6 & 0.69 & 286.5 & 286.5 & $<0.1$ & 26561.0 & 26561.0 & $<0.1$ \\
\hline Villa_INC_Worker_TO_MCV04_CIN03 & 1 & 1 & 1 & 73.1 & 148.8 & 103.59 & 21922.9 & 23708.5 & 8.14 \\
\hline Villa_INC_Worker_TO_MCV04_C & 1 & 1 & 1 & & 217.8 & 155.91 & & 23916.5 & 10 \\
\hline Villa_INC_Worker_TO_MCO05_C & 1 & 1 & 1 & & 131.6 & 76.65 & 20465.9 & 22155.0 & 8.25 \\
\hline Villa_INC_Worker_TO_MCO05_CIN02 & 1 & 1 & 1 & 88.6 & 200.8 & 126.72 & 20340.8 & 22365.7 & 9.95 \\
\hline
\end{tabular}




\section{Conclusion}

In this paper, a novel simplified building model has been presented, together with an algorithm, implemented in the software SEAS Light, to be applied to building energy audits. The routine is based on a single lumped capacity model, but some input parameters (periodic thermal transmittance, time shift, and areal heat capacity of opaque walls) are based on analytical solutions of the dynamics of continuous walls, according to EN ISO 13786:2007. Only three tuning coefficients are used, and they can be obtained from energy billings (yearly heating and cooling energy uses). First, the model has been validated on EN 15265:2007. Then, the results of 75 additional simulations have been compared with those obtained through the widespread dynamic energy building software TRNSYS. The estimated seasonal energy demands perfectly match in 63 of 75 cases. In the remaining tests, the tuning procedure has not been performed, because the reference cooling energy demand is lower than $100 \mathrm{kWh} /$ year. However, also in these cases, the algorithm provides results of the same order of magnitude of TRNSYS. Most notably, for all the examined cases, the values of the tuning parameters are close to the unity, indicating the reliability and robustness of the described physical model. We can conclude that SEAS Light represent a viable energy tool for building energy estimations, particularly suitable for energy audits. Additionally, the low computational time and the high accuracy showed by the model make the algorithm a valuable tool for energy optimization analyses, both in terms of energy efficiency actions, RES integration, and advanced control strategies. Future works will furtherly investigate the 75 test cases, seeking trends in the tuning parameters and exploring the applicability of the algorithm to retrofit measures and to energy estimations at shorter time scales.

\section{Nomenclature}

A: area $\left[\mathrm{m}^{2}\right]$

$b_{t r, U}$ : correction factor for the heat transfer through the ground

$\mathrm{c}_{\mathrm{p} \text {,air: }}$ specific heat at constant pressure of external air $[\mathrm{J} /(\mathrm{kgK})]$

$\mathrm{F}_{\mathrm{sh}, \mathrm{gl}}$ : shutter reduction factor

$\mathrm{F}_{\mathrm{sh}, \mathrm{ob}}$ : shading reduction factor

$\mathrm{F}_{\mathrm{sh}, \mathrm{ob}}^{\text {diff }}$ : shading reduction factor for the diffuse radiation

$\mathrm{F}_{\mathrm{f}}$ : ratio between frame area and total window area

FV: form factor between the building element and the sky g: solar energy transmittance

$\mathrm{h}_{\text {ext }}$ : external heat transfer coefficient

İ: global normal solar radiation $\left[\mathrm{W} / \mathrm{m}^{2}\right.$ ]

$\mathrm{K}_{\mathrm{int}}$ : areal heat capacity of a wall $\left[\mathrm{Wh} /\left(\mathrm{m}^{2} \mathrm{~K}\right)\right]$

$\mathrm{K}_{\mathrm{z}}$ : equivalent thermal capacity of the whole building $[\mathrm{Wh} / \mathrm{K}]$

$\dot{\mathrm{m}}_{\text {vent }}$ : mass flow rate $[\mathrm{kg} / \mathrm{s}]$

Q: thermal power [W]
$\dot{\mathrm{Q}}_{\text {sky }}$ : long wavelenght thermal radiation $\left[\mathrm{W} / \mathrm{m}^{2}\right]$

Q: thermal energy [Wh]

$\mathrm{Q}_{\mathrm{REF}}$ : seasonal thermal energy demand reference value [Wh]

$\mathrm{Q}_{\text {Tот }}$ : simulated seasonal thermal energy demand [Wh]

$\mathrm{R}_{\mathrm{sh}, \mathrm{q}}$ : additional thermal resistance of shutters $\left[\mathrm{m}^{2} \mathrm{~K} / \mathrm{W}\right]$

$\mathrm{T}$ : temperature $\left[{ }^{\circ} \mathrm{C}\right]$

$\mathrm{T}_{\text {avg }}$ : monthly average outdoor temperature $\left[{ }^{\circ} \mathrm{C}\right]$

$\mathrm{T}_{\text {sol-air }}$ : sol-air temperature $\left[{ }^{\circ} \mathrm{C}\right]$

$\mathrm{T}_{\text {sky }}$ : apparent sky temperature $\left[{ }^{\circ} \mathrm{C}\right]$

$\mathrm{U}$ : thermal transmittance $\left[\mathrm{W} /\left(\mathrm{m}^{2} \mathrm{~K}\right)\right]$

$\mathrm{U}_{\mathrm{sh}, \mathrm{w}}$ : overall steady-state thermal transmittance (window, frame, shutter) $\left[\mathrm{W} /\left(\mathrm{m}^{2} \mathrm{~K}\right)\right]$

$\mathrm{U}_{\mathrm{q}}$ : overall steady-state thermal transmittance (window and frame $)\left[\mathrm{W} /\left(\mathrm{m}^{2} \mathrm{~K}\right)\right]$

\section{Greek letters}

$\alpha_{\mathrm{s}}$ : solar radiation absorptivity

$\alpha_{\mathrm{SOL}}$ : solar gains through windows tuning parameter

$\beta$ : thermal capacity tuning parameter

$\beta_{\mathrm{S}}$ : surface tilt angle

$\varepsilon$ : surface emissivity

$\sigma$ : Stefan-Boltzmann constant, $5.67 \cdot 10^{-8} \mathrm{~W} /\left(\mathrm{m}^{2} \mathrm{~K}^{4}\right)$

$\phi$ : time shift [h]

\section{Superscripts}

set: set point

t: time step

\section{Subscripts}

C: cooling

dyn: dynamic

$\mathrm{H}$ : heating

l: thermal loss/gain

p: opaque wall

stat: steady-state

$\mathrm{w}$ : window (frame included)

z: thermal zone

\section{References}

Buonomano, A., \& Palombo, A. (2014). Building energy performance analysis by an in-house developed dynamic simulation code: An investigation for different case studies. Applied Energy 113, 788-807.

Coakley, D., Raftery, P., \& Keane, M. (2014). A review of methods to match building energy simulation models to measured data. Renewable and Sustainable Energy Reviews 37, 123-141.

Conti, P., Schito, E., \& Testi, D. (2019). Cost-benefit analysis of hybrid photovoltaic/thermal collectors in a nearly zero-energy building. Energies 12, 1582.

Corrado, V., Mechri, H. E., \& Fabrizio, E. (2007). Building energy performance assessment through 
simplified models: application of the ISO 13790 quasi-steady state method. Proceedings: Building Simulation 2007.

Crawley, D. B., Hand, J. W., Kummert, M., \& Griffith, B. T. (2008). Contrasting the capabilities of building energy performance simulation programs. Building and Environment 43 (4), 661-673.

D’Ettorre, F., De Rosa, M., Conti, P., Schito, E., Testi, D., \& Finn, D. P. (2018). Economic assessment of flexibility offered by an optimally controlled hybrid heat pump generator: A case study for residential building. Energy Procedia 148, 1222-1229.

D'Ettorre, F., Conti, P., Schito, E., \& Testi, D. (2019). Model predictive control of a hybrid heat pump system and impact of the prediction horizon on costsaving potential and optimal storage capacity. Applied Thermal Engineering 148, 524-535.

Danza, L., Belussi, L., Meroni, I., Salamone, F., Floreani, F., Piccinini, A., \& Dabusti, A. (2016). A simplified thermal model to control the energy fluxes and to improve the performance of buildings. Energy Procedia 101, 97-104.

Date, J., Candanedo, J. A., \& Athienitis, A. K. (2016). Control-oriented Modelling of Thermal Zones in a House: a Multi-level Approach. International High Performance Buildings Conference. Paper 229.

Evangelisti, L., Battista, G., Guattari, C., Basilicata, C., \& de Lieto Vollaro, R. (2014). Analysis of Two Models for Evaluating the Energy Performance of Different Buildings. Sustainability 6, 5311-5321.

Grassi, W., Conti, P., Schito, E., \& Testi, D. (2015). On sustainable and efficient design of ground-source heat pump systems. J. Phys. Conf. Ser. 655 (1), 012003.

Italian Energy Efficiency Action Plan. (2017).

Italy's Energy Efficiency annual report - Executive summary. (2016).

Klein, S. (2010). A Transient System Simulation Program (TRNSYS 17) Manual.

Kramer, R., van Schijndel, J., \& Schellen, H. (2012). Simplified thermal and hygric building models: a literature review. Frontiers of Architectural Research 1, 318-325.

Lü, X., T.Lu, \& Viljanen, M. (2006). A new analythical method to simulate heat transfer process in buildings. Appl. Thermal Eng. 26, 1901-1909.

O’Callaghan, P. W., \& Probert, S. D. (October 1977). Technical note - Sol Air Temperature. Applied Energy 3, 307-311.

Pernigotto, G., \& Gasparella, A. (2013). Quasi-steady state and dynamic simulation approaches for the calculation of building energy needs: Part 2 thermal gains. Building Simulation Applications BSA 2013 1st IBPSA-Italy Conference. Bolzano.

Schito, E., Testi, D., Conti, P., \& Grassi, W. (2015). Validation of SEAS, a quasi-steady-state tool for building energy audits. Energy Procedia 78, 31923197.

Schito, E., Conti, P., \& Testi, D. (2018a). Robust microclimate control for artwork preservation in response to extreme climatic conditions: Simulation of museum halls for temporary exhibitions with a validated dynamic tool. IOP Conf. Ser. Mater. Sci. Eng 364(1), 012008.

Schito, E., Conti, P., \& Testi, D. (2018b). Multi-objective optimization of microclimate in museums for concurrent reduction of energy needs, visitors' discomfort and artwork preservation risks. Applied Energy 224, 147-159.

Stephenson, D. G. (1957). Thermal Radiation and its Effect on the Heating and Cooling of Buildings. Report No 121 of the Division of Building Research.

Testi, D., Menchetti, E., Schito, E., \& Grassi, W. (2013). An open access tool for building energy audits harmonizing European standards. Building Simulation Applications, 225-232.

Testi, D., Schito, E., Menchetti, E., \& Grassi, W. (2014). Energy retrofit of an office building by substitution of the generation system: performance evaluation via dynamic simulation versus current technical standards. J. Phys. Conf. Ser. 547 (1), 012018.

Testi, D., Schito E., Tiberi, E., Conti, P., \& Grassi, W. (2015a). Building energy simulation by an in-house full transient model for radiant systems coupled to a modulating heat pump. Energy Procedia 78, 11351140 .

Testi, D., Schito, E., Menchetti, E., Conti, P., Della Vista, D., Pellegrini, G., Tiberi, E., Grassi, W., Signoretti, P., \& Fasano, G. (2015b). Il software SEAS per le diagnosi energetiche: interventi di assistenza $e$ formazione e sviluppo di un modello semplificato per gli edifici ad uso residenziale, Report RdS/PAR2014/068.

Testi, D., Schito, E., \& Conti, P. (2016a). Cost-optimal Sizing of Solar Thermal and Photovoltaic Systems for the Heating and Cooling Needs of a Nearly Zeroenergy Building: Design Methodology and Model Description. Energy Procedia 91, 517-527.

Testi, D., Schito, E., \& Conti, P. (2016b). Cost-optimal Sizing of Solar Thermal and Photovoltaic Systems for the Heating and Cooling Needs of a Nearly ZeroEnergy Building: The Case Study of a Farm Hostel in Italy. Energy Procedia 91, 528-536.

Van der Veken, J., Saelens, D., Verbeeck, G., \& Hens, H. (2004). Comparison of steady-state and dynamic building energy simulation programs. International Buildings IX ASHRAE conference.

Zhao, H., \& Magoulès, F. (2012). A review on the prediction of building energy consumption. Renewable and Sustainable Energy Reviews 16, 3586-3592. 